\title{
JESP Editorial
}

Virtual Special Issue: Racism and Justice for Black Lives, final, 5 July 2020

As social psychology grew during the mid-20th century, its research was driven by a need to demonstrate, explain, and fight the harmful effects of racism, especially in Nazi Germany and the segregated United States. As a field, our research findings on racial prejudice and discrimination have influenced millions of people through education, media, policy, and even court cases. At the same time, and despite its historical focus, social psychology is not free of wrong steps on racial issues. As an institution, our field could do more to support representation and equality, both within itself and in society at large. We also benefit from reflection on our priorities, especially at moments in history when more direct and broad-based confrontations of racism arise.

Such a moment happened in the 1960's and 1970's, when social protests led to a taking stock, a "crisis of relevance" about the concerns and methods of social psychology research (Giner-Sorolla, 2019). Such a moment is now. The outright murders of George Floyd, Breonna Taylor, and many more African-American people at the hands of police initiated a national and global wave of protest, intensified by the visibility of violent policing responses. In June 2020, a worldwide conversation is under way about the commitment of society to treating Black, Indigenous, and other people of color fairly. In the history of social psychology, as in this year's events, there is a focus on AfricanAmerican people which reflects the long history of racism there, and inspires efforts by and for racially discriminated-against peoples worldwide.

These movements for justice have inspired many institutions to respond with statements and initiatives. At the Journal of Experimental Social Psychology, we, the Editors, have been discussing among ourselves and with our publisher the way we treat research based on different populations, the terminology used in our articles, the ability to check representation in the article publication process, and the means of recruiting the reviewers who make up our Editorial Board. We will issue an update in September of this year, on the JESP website, detailing what action we have taken on these and related issues.

As a first step, JESP is making available this Virtual Special Issue on Racism and Justice for Black Lives. We highlight a selection of research articles from the past ten years of our journal with relevance to racism and to the special legacy of discrimination faced by African-American people.

These primary research articles are intended for the use of educators, psychologists, journalists, communicators, and organizers and will remain open access until at least the end of 2020. This selection is not a definitive list of relevant research published in JESP, and we encourage readers to investigate the larger body of research on each of these topics.

In the spirit of reflection, we identify three limitations of research in our field. First, no single experimental research article should be considered definitive. Findings open up questions and supply evidence and remain subject to revision as future research strives to replicate, build on, or challenge them. Even systematic reviews, like this issue's article meta-analyzing the shooter bias literature (Mekawi \& Bresin, 2015), are often based on literatures that are biased towards publishing statistically significant results. At JESP we are aware of the challenges faced in ensuring published results are robust and replicable. Since 2015 we have step-by-step strengthened our requirements to guard against selective reporting, to improve statistical inference, methodological rigour, and to encourage replications and Registered Reports, counteracting publication bias. Regardless of the year it was published, each article should be looked at carefully and in the wider context of the literature. 
Second, the perspective of our discipline is limited. Experimental social psychology by its nature most often confronts racism by studying the prejudice of individuals in aggregate. We are skilled at experimentally varying contexts to demonstrate bias statistically, in the lab and in the field. Experimental methods are not so well suited to study direct reactions to racism among its targets, because of ethical concerns that arise when manipulating potentially painful experiences. Other disciplines, too, are likely better placed to address systemic racism by identifying the larger-scale prevalence of discrimination. Finally, in our focus upon understanding problems, we often neglect to follow through and develop solutions, with less value placed on applications of theory compared to insights about processes (Giner-Sorolla, 2019; Lewis, 2020). These studies, then, are only part of a fuller understanding of racism. A complete understanding must also embrace larger scale perspectives on social systems and interventions, and smaller scale insights from personal and qualitative accounts. And of course, research can only help to change society after putting in the political work necessary to ensure that those in power will listen to it.

Third, over the history of social psychology, research on racism has tended to focus on the attitudes, perceptions and behaviors of White people, more than on the experiences of non-White people targeted by racism. More recently, there has also been a focus on subtle and implicit forms of prejudice, rather than blatant and explicit ones. Both priorities need to be re-examined especially urgently, in light of a recent worldwide erosion of anti-racist norms in politics. and in light of ongoing calls to foreground the agency of those disadvantaged by racism. Likely causes of these skewed priorities include the predominantly White perspectives of researchers in the field, together with a historical reliance on student participant pools who tend to be mostly White and to profess more liberal beliefs on race than most other White people.

In the field of intergroup dehumanization, for example, largely White research teams initially developed subtle and indirect measures based on the assumption that participants would not explicitly liken people of other racialised groups and nationalities to animals (Kteily \& Bruneau, 2017). Perhaps it is not a coincidence that two researchers of color, G. Tendayi Viki and Nour Kteily, independently led demonstrations of explicit group-based dehumanization, challenging the assumption that dehumanising attitudes can only be expressed subtly (Viki, Winchester et al, 2007; Kteily \& Bruneau, 2017). Similar challenges have arisen to studying implicit over explicit modes of prejudice, including an article in our Virtual Special Issue that examines the consequences for progress in racialised issues of attributing bias to implicit processes (Daumeyer, Onyeador, Brown, \& Richeson, 2019).

Many of the articles in this special issue benefit from the leadership and contributions of AfricanAmerican authors, whose perspectives and personal experiences inform and deepen our field's overall scholarship on racism. That said, we want to also avoid the implication that scholars of color only study racism, and acknowledge that many authors from African-American, African, and Africandiaspora backgrounds follow their passion and curiosity to succeed with research in other areas of social psychology. To give only a few examples based on recent first authors in JESP, these areas include justice (Owuamalam \& Spears, 2020), perspective taking (Laurent \& Meyers, 2011; Laurent, Nuñez \& Schweitzer, 2015); mental illness stigma (West \& Brückmüller, 2013; West \& Turner, 2014), weight stigma (Derricks \& Earl, 2019) and educational motivation (Destin \& Oyserman, 2010).

The Virtual Special Issue itself is organized according to topics, each with several representative articles from the past ten years of JESP. We thought it important to sample research on: how people perceive and label racial identities (Gaither et al., 2018; Hall et al., 2015); the entanglement of the concept of race with social ideologies about wealth and power (Brown-lannuzzi et al., 2019; Hudson et al., 2019); racial perceptions that enable and react to lethal force in law enforcement (Cooley \& 
Brown-lannuzzi, 2019; Mekawi \& Bresin, 2015); how people react to expressions and explanations of prejudice (Daumeyer et al., 2019; Thai et al., 2019); how White people deal with racial advantage (Carter \& Murphy, 2017; Philips \& Lowery, 2015); and the challenges arising at the intersection of Blackness and other identities (Petsko \& Bodenhausen, 2019; Pietri et al., 2018; Rosette \& Livingstone, 2012).

In making these limited selections, we are conscious of the many other articles in the journal that expand on these topics, and that cover other relevant issues such as racial stereotyping and subtyping, prejudice reduction through contact and training, racial bias in health- and educationrelated judgments, and ethnic factors in facial perception. This Special Issue is only an opening to encourage further study and discussion.

In conclusion, we at JESP affirm that Black lives matter. We offer this selection of articles as a way to partially understand the obstacles to this affirmation and encourage further research that addresses some of the hidden assumptions and omissions in the research we published. We will take other measures toward ensuring that these values are reflected in our future decisions.

On behalf of the Editors, Roger Giner-Sorolla, Editor in Chief

\section{References: Virtual Special Issue}

Brown-lannuzzi, J. L., Cooley, E., McKee, S. E., \& Hyden, C. (2019). Wealthy Whites and poor Blacks: Implicit associations between racial groups and wealth predict explicit opposition toward helping the poor. Journal of Experimental Social Psychology, 82, 26-34.

Carter, E. R., \& Murphy, M. C. (2017). Consensus and consistency: Exposure to multiple discrimination claims shapes Whites' intergroup attitudes. Journal of Experimental Social Psychology, 73, 24-33.

Cooley, E., \& Brown-lannuzzi, J. (2019). Liberals perceive more racism than conservatives when police shoot Black men-But, reading about White privilege increases perceived racism, and shifts attributions of guilt, regardless of political ideology. Journal of Experimental Social Psychology, 85, 103885.

Gaither, S. E., Babbitt, L. G., \& Sommers, S. R. (2018). Resolving racial ambiguity in social interactions. Journal of Experimental Social Psychology, 76, 259-269.

Hall, E.V., Phillips, K.W., \& Townsend, S.M. (2015). A rose by any other name? The consequences of subtyping "African-Americans" from "Blacks." Journal of Experimental Social Psychology, 56, 183-190

Hudson, S. K. T. J., Cikara, M., \& Sidanius, J. (2019). Preference for hierarchy is associated with reduced empathy and increased counter-empathy towards others, especially out-group targets. Journal of Experimental Social Psychology, 85, 103871.

Petsko, C. D., \& Bodenhausen, G. V. (2019). Racial stereotyping of gay men: Can a minority sexual orientation erase race?. Journal of Experimental Social Psychology, 83, 37-54.

Pietri, E. S., Johnson, I. R., \& Ozgumus, E. (2018). One size may not fit all: Exploring how the intersection of race and gender and stigma consciousness predict effective identity-safe cues for Black women. Journal of Experimental Social Psychology, 74, 291-306.

Rosette, A. S., \& Livingston, R. W. (2012). Failure is not an option for Black women: Effects of organizational performance on leaders with single versus dual-subordinate identities. Journal of Experimental Social Psychology, 48(5), 1162-1167. 
Thai, M., Stainer, M. J., \& Barlow, F. K. (2019). The "preference" paradox: Disclosing racial preferences in attraction is considered racist even by people who overtly claim it is not. Journal of Experimental Social Psychology, 83, 70-77.

Other References

Derricks, V., \& Earl, A. (2019). Information targeting increases the weight of stigma: Leveraging relevance backfires when people feel judged. Journal of Experimental Social Psychology, 82, 277-293.

Destin, M., \& Oyserman, D. (2010). Incentivizing education: Seeing schoolwork as an investment, not a chore. Journal of Experimental Social Psychology, 46(5), 846-849.

Giner-Sorolla, R. (2019). From crisis of evidence to a "crisis" of relevance? Incentive-based answers for social psychology's perennial relevance worries. European Review of Social Psychology, 30(1), 1-38.

Kteily, N. S., \& Bruneau, E. (2017). Darker demons of our nature: The need to (re) focus attention on blatant forms of dehumanization. Current Directions in Psychological Science, 26(6), 487-494.

Laurent, S. M., \& Myers, M. W. (2011). I know you're me, but who am I? Perspective taking and seeing the other in the self. Journal of Experimental Social Psychology, 47(6), 1316-1319.

Laurent, S. M., Nuñez, N. L., \& Schweitzer, K. A. (2015). The influence of desire and knowledge on perception of each other and related mental states, and different mechanisms for blame. Journal of Experimental Social Psychology, 60, 27-38.

Lewis, N. A., Jr. (2020). What I've learned about being a Black scientist. Retrieved from https://www.sciencemag.org/careers/2020/06/what-ive-learned-about-being-blackscientist . doi:10.1126/science.caredit.abd3589

Owuamalam, C. K., \& Spears, R. (2020). Do humans possess an autonomous system justification motivation? A Pupillometric test of the strong system justification thesis. Journal of Experimental Social Psychology, 86, 103897.

Viki, G. T., Winchester, L., Titshall, L., Chisango, T., Pina, A., \& Russell, R. (2006). Beyond secondary emotions: The infrahumanization of outgroups using human-related and animal-related words. Social Cognition, 24(6), 753-775.

West, K., \& Bruckmüller, S. (2013). Nice and easy does it: How perceptual fluency moderates the effectiveness of imagined contact. Journal of Experimental Social Psychology, 49(2), 254-262.

West, K., \& Turner, R. (2014). Using extended contact to improve physiological responses and behavior toward people with schizophrenia. Journal of Experimental Social Psychology, 50, 57-64. 